\title{
Ponencia presentada a la primera reunión del grupo de carbonatación de la RILEM, celebrado en París (CERILH) el 29 de marzo de 1971
}

En el Instituto Eduardo Torroja, en primer lugar, se ha hecho un estudio crítico sobre la mayoría de los trabajos aparecidos hasta la fecha sobre el tema de la carbonatación.

Aunque a primera vista la carbonatación parece ser un tema muy trillado, hay una serie de puntos en los que existen ciertas contradicciones; ya que, por ejemplo, Verbeck en su trabajo "Carbonatación del cemento portland hidratado (P.C.A.; Bull. n. ${ }^{\circ} 87$; Washington, 1958) dice: "Cuanto más cantidad de $\mathrm{CO}_{2}$ haya en la atmósfera, más elevada será la retracción final..."; mientras que Kroone en su trabajo "Influencia de un mojado y secado repetidos, sobre la carbonatación" (Zement-Kalk-Gips, número 1; enero de 1966), dice: “...La retracción de carbonatación es bastante pequeña, si el secado es rápido y la concentración del $\mathrm{CO}_{2}$ es elevada; pero es más fuerte si el secado se efectúa lentamente y la concentración del $\mathrm{CO}_{2}$ es pequeña...".

En general, las conclusiones que más abundan son:

1. La carbonatación es más o menos eficaz (o sea, se obtienen mejores resistencias mecánicas, menor expansión de volumen, mayor resistencia al ataque de los sulfatos), según las condiciones del curado previo de las probetas.

2. $\quad$ La carbonatación parece que se efectúa mejor a humedades relativas, más bien bajas (comprendidas entre 50 y $55 \%$ de h.r.).

3. ${ }^{2}$ Dada la atacabilidad del $\mathrm{CO}_{3} \mathrm{Ca}$ en un medio ácido, para que un tratamiento de carbonatación sea eficaz a efectos de la durabilidad, ésta debe entenderse frente a disoluciones de sales alcalinas o neutras.

4. ${ }^{2} \quad$ La carbonatación actúa de diferente manera sobre diferentes cementos, según la naturaleza de éstos.

5. ${ }^{a}$ Cuanto más permeables (baja relación A/C) sean los morteros y hormigones, mayor es la profundidad de carbonatación y, por lo tanto, su efecto será más eficaz.

6. Es una de las más importantes: El efecto de la carbonatación sobre las armaduras del hormigón. 
La reacción

$$
\mathrm{Ca}(\mathrm{OH})_{2}-\mathrm{CO}_{3} \mathrm{Ca}-\mathrm{Ca}\left(\mathrm{CO}_{3} \mathrm{H}\right)_{2}
$$

influye sobre el grado de acidez del hormigón [ $\mathrm{pH}$ y reserva alcalina de $\left.\mathrm{Ca}(\mathrm{OH})_{2}\right]$. El hidróxido cálcico hace especialmente alcalino al hormigón fresco. $\mathrm{Su} \mathrm{pH}$ es aproximadamente 12. La carbonatación hace bajar gradualmente el $\mathrm{pH}$ hasta un valor aproximado de 9. La reacción carbonato-bicarbonato, lo hace descender aún más. Hasta qué punto desciende, depende del contenido de $\mathrm{CO}_{2}$ en el ambiente inmediato. En contacto con una atmósfera normal que contiene aproximadamente $0,03 \%$ de $\mathrm{CO}_{2}$, se obtiene en el hormigón un valor del $\mathrm{pH}$ de 8,4. Por ejemplo, en el espacio de aire, en un sistema de desagüe, donde el contenido de dióxido de carbono se eleva en promedio hasta un $1 \%$, el pH del hormigón puede descender hasta 7,4. Los electrólitos externos, que tal vez penetren en el hormigón, pueden contribuir a un descenso del $\mathrm{pH}$ todavía mayor.

La corrosión del acero en el hormigón armado se basa en las diferencias del potencial electroquímico. La velocidad de la corrosión depende del grado de acidez del ambiente. $\mathrm{El}$ acero dentro del hormigón fresco, debido a la alcalinidad de éste, se encuentra en un campo pasivo donde no puede producirse ninguna corrosión. Cuando desciende el $\mathrm{pH}$ del ambiente se modifican las circunstancias de tal forma que desaparece la pasividad del acero, siendo inminente el peligro de corrosión. La carbonatación del hormigón que rodea el acero, baja el $\mathrm{pH}$ hasta tal punto que facilita la corrosión.

Paralelamente a esta labor bibliográfica, y a modo de tentativa, también se han efectuado dos series de ensayos sobre prismas de mortero poroso 1:2 de $1 \times 1 \times 6 \mathrm{~cm}$ (prismas de KOCH Y STEINEGGER): una serie carbonatada y otra serie sin carbonatar, con objeto de comparar el poder inhibidor de la carbonatación frente al ataque de los sulfatos.

Se estudiaron ocho cementos de distinta naturaleza:

1 tipo portland, clase portland de alta resistencia inicial, categoría P-450.

2 tipo portland, clase resistente a los sulfatos, categoría PAS-350 (uno de procedencia española y otro de procedencia alemana).

1 tipo siderúrgico, clase portland de alto horno, categoría PHA-250.

1 tipo siderúrgico, a base de un $70 \%$ de clínker y un $30 \%$ de escoria de alto horno, categoría SC-250.

1 tipo siderúrgico, clase sobresulfatado, categoría SF-250.

1 tipo puzolánico, clase y categoría PUZ-350.

1 tipo aluminoso, clase y categoría CA-350.

Los prismas, después de un curado previo de 24 horas en los moldes, se desmoldaron y se dejaron en cámara de humedad (humedad relativa $100 \%$ ), durante 28 días.

A los 28 días se sacaron de la cámara, se enjugaron con un paño y se airearon durante 1 hora; después se colocaron dentro de un desecador, donde se dejaron durante 3 días en una atmósfera de $\mathrm{CO}_{2}$ de secado y a una temperatura ambiente lo más homogénea posible y aproximada a $20^{\circ} \mathrm{C}$.

Una vez terminado el período de carbonatación, se sacaron los prismas del desecador y se 
introdujeron en las disoluciones agresivas diez prismas por cada edad y por cada disolución agresiva.

Las disoluciones agresivas fueron:

Agua filtrada, donde se conservaron los prismas-testigo.

Disolución saturada de $\mathrm{SO}_{4} \mathrm{Ca}$.

Agua de mar artificial.

Mezcla al $50 \%$ de disolución saturada de $\mathrm{SO}_{4} \mathrm{Ca}$ y $50 \%$ de disolución de $\mathrm{SO}_{4} \mathrm{Mg}$ de la misma concentración que el $\mathrm{SO}_{4} \mathrm{Ca}$ en disolución saturada.

Disolución de sulfato sódico al $5 \%$.

Disolución de sulfato magnésico al $10 \%$.

Disolución de sulfato amónico al $5 \%$.

Disolución de cloruro amónico al $5 \%$.

Las edades estudiadas fueron: 1, 3, 6, 9 y 12 meses; al final de cada edad se midieron las resistencias a flexotracción. Como valores individuales de rotura se tomaron, por cada disolución y por cada edad estudiada, las 'medias aritméticas de los diez prismas rotos.

Los resultados obtenidos en esta serie de ensayos serán publicados en breve como "Cuadernos de Investigación" del I.E.T.c.c.

A la vista de los resultados obtenidos en nuestra serie de ensayos, así como de las conclusiones que de la bibliografía estudiada hemos podido observar, creemos que los puntos fundamentales que se deberían tener en cuenta para próximos trabajos experimentales son:

1. Estudio de las condiciones y duración óptimas del curado previo a la carbonatación, para la mayor eficacia de ésta.

2. Determinación del agua evaporable y del agua no evaporable y estudio de su influencia en la carbonatación.

3. Determinación de la porosidad: volumen, tamaño, forma y distribución de poros.

El paso inmediato sería:

4. ${ }^{\circ}$ Fijar las condiciones óptimas de la carbonatación propiamente dicha, para que ésta sea eficaz:

a) influencia de la humedad relativa de la atmósfera de $\mathrm{CO}_{2}$ en la carbonatación;

b) influencia de la presión y temperatura de carbonatación y determinación de los valores óptimos de ambas.

Otro estudio a más largo plazo, podría ser el de acelerar el proceso de carbonatación, combinándolo con un curado previo hidrotérmico con vapor, de las piezas de hormigón. 